\title{
Comparison of the Hemodynamic Alterations in Normotensive and Preeclamptic Pregnant Woman Posted for Cesarean Section under Subarachnoid Block
}

\author{
Manasij Mitra1, Dipanwita Basu², Tanmoy Ganguly ${ }^{3}$, Sandeep Kumar Kar ${ }^{3 *}$ and Sujit Chaterjee ${ }^{1}$ \\ ${ }^{1}$ Anaesthesiology, M.G.M Medical College, Kishanganj, India \\ ${ }^{2}$ Anaesthesiology, District Hospital Siliguri, West Bengal, India \\ ${ }^{3}$ Cardiac Anaesthesiology, Institute of Postgraduate Medical Education and Research, Kolkata, India
}

\begin{abstract}
Introduction: Anesthesia for cesarean section in a patient with preeclampsia is far more complicated than an otherwise normal pregnancy for several reasons. Apart from the risks of high incidence of intrauterine growth restriction, fetal distress and prematurity, there are risk of increased perioperative morbidity due to altered hemodynamics
\end{abstract}

Material and methods: This study was conducted on 100 booked pregnant woman of ASA physical status I and II (Normotensive) or III (Preeclamptic), between 19 to 30 years of age, carrying a live, mature, healthy, single fetus posted for elective cesarean section. Patients were counseled during preoperative examination and 50 normotensive and 50 preeclamptic patients were recruited for this study after obtaining informed consent from each of the patient in their own language.

Result and analyses: In this study, the authors found significant differences in SBP, DBP and MAP at different point of times in both the groups. One probable explanation of this may be the use of invasive arterial blood pressure monitoring in place of non-invasive monitoring unlike other studies. Also the preoperative blood pressure values were significantly different in both the groups. More phenylephrine consumption was noted in the normotensive group.

Conclusion: subarachnoid block in preeclampsia patients associated with better perioperative hemodynamic stability, less hypotension, less vasopressor consumption and more gradual blood pressure changes.

Keywords: Preeclampsia; Perioperative hemodynamic stability; Phenylephrine; Subarachnoid block

\section{Introduction}

Successful anesthesia for cesarean section involves delivery of a live, mature, healthy baby uneventfully with no additional morbidity or mortality to the mother. Analysis of anesthesia-related deaths during obstetric delivery in the United States from 1979-1990 indicated that general anesthesia is related to 16.7 times increased mortality risk compared with neuraxial blockade for cesarean delivery [1]. Recent advances in anesthesia drugs and techniques reduced that figure to 1.7 times in between 1979 and 2002 [2], but still more favourable outcomes are found with neuraxial anesthesia. Less morbidity and mortality, less failure, dense anesthesia, easy technique, provision of adequate operating conditions in a shorter time and several other advantages have placed neuraxial anesthesia particularly subarachnoid block as a more preferable mode of anesthesia for elective cesarean section to epidural block or general anesthesia [1-5].

Anesthesia for cesarean section in a patient with preeclampsia is far more complicated than an otherwise normal pregnancy for several reasons. Apart from the risks of high incidence of intrauterine growth restriction, fetal distress and prematurity, there are risk of increased perioperative morbidity due to altered hemodynamics in these patients [6-9]. The ideal technique for anesthesia had been a long controversy among the obstetric anesthesiologists [10-12]. Although spinal anesthesia had been considered as the preferred technique by many [13-16], the risk of hypotension and altered hemodynamics has influenced the choice of anesthesia.

In this background, the authors conducted a study to evaluate and compare the hemodynamic alterations in both normotensive and preeclamptic pregnant woman posted for cesarian section under spinal anesthesia.

\section{Methodology}

Ethical clearance was obtained from Institutional Research Oversight Committee. This study was conducted on 100 booked pregnant woman of ASA physical status I and II (Normotensive) or III (Preeclamptic), between 19 to 30 years of age, carrying a live, mature, healthy, single fetus posted for elective cesarean section. Patients were counseled during preoperative examination and 50 normotensive and 50 preeclamptic patients were recruited for this study after obtaining informed consent from each of the patient in their own language. Patients with chronic hypertension, diabetes mellitus, known cardiac disease, renal disease, and coagulopathy; with contraindication to subarachnoid block, known sensitivity to the study drugs and patients refusing to either regional anesthesia or the study technique were also

*Corresponding author: Sandeep Kumar Kar, Assistant Professor, Cardiac Anaesthesiology, Institute of Postgraduate Medical Education and Research, Kolkata, India, Tel: +919477234900; E-mail: sndpkar@yahoo.co.in

Received April 18, 2016; Accepted April 26, 2016; Published May 10, 2016

Citation: Mitra M, Basu D, Ganguly T, Kar SK, Chaterjee S (2016) Comparison of the Hemodynamic Alterations in Normotensive and Preeclamptic Pregnant Woman Posted for Cesarean Section under Subarachnoid Block. J Cardiovasc Dis Diagn 4: 242. doi:10.4172/2329-9517.1000242

Copyright: (๑) 2016 Mitra M, et al. This is an open-access article distributed under the terms of the Creative Commons Attribution License, which permits unrestricted use, distribution, and reproduction in any medium, provided the original author and source are credited. 
excluded from the study. Any patients showing signs or alarming symptoms for eclampsia were also excluded from the study and managed with $\mathrm{IV}_{\mathrm{MgSO}}^{4}$ wherever indicated.

All antihypertensives were continued till the day of surgery. Patients received oral ranitidine $(150 \mathrm{mg})$ and oral metoclopramide $(10 \mathrm{mg})$ at the morning of the surgery. After receiving the patient in the operating room, documents were checked, a brief clinical examination was done and standard ASA monitors were attached including ecg, pulse oxymetry and temperature probe. A radial arterial line was established with a $20 \mathrm{G}$ radial arterial cannula and invasive blood pressure was monitored. Baseline heart rate (HR), systolic blood pressure (SBP), diastolic blood pressure (DBP) and mean arterial pressure (MAP) was recorded. After establishing IV access with an $18 \mathrm{G}$ cannula $20 \mathrm{ml} / \mathrm{kg}$ lactated ringer solution (RL) was administered for prehydration.

After proper aseptic precaution spinal subarachnoid block (SAB) was performed by an anesthesiologist blinded to the study in the sitting position, at L3-L4 or L4-L5 intervertebral space through a midline approach by a $26 \mathrm{G}$ Qunicke type spinal needle and $2.5 \mathrm{ml}$ of $0.5 \%$ hyperbaric bupivacaine was administered after confirming needle location Patient was placed supine with a $10 \mathrm{~cm}$ wedge under right buttock to prevent aortocaval compression. All patients received moist oxygen ( 2 litre/minute) by a binasal cannula and RL infusion was continued. Surgery was allowed after adequate sensory and motor block was confirmed. Immediately after delivery of head of the baby oxytocin 2 IU was administered over 1 minute followed by infusion at the rate of $10 \mathrm{IU} / \mathrm{Hr}$ for 4 hours followed by $5 \mathrm{IU} /$ Hour for 12 hours.

Intraoperative blood loss of the mother was assessed from the drainage in suction bottles and checking the swabs and mops used and appropriate replacement done. HR, SBP, DBP and MAP were recorded at 12 specified period:

T1: Immediately after volume preload

T2: Immediately after SAB

T3: 4 minutes after SAB

T4: 6 minutes after $S A B$

T5: 8 minutes after SAB

T6: 10 minutes after $\mathrm{SAB}$

T7: After skin incision;

T8: After uterine incision

T9: After newborn delivery

T10: After placental delivery

T11: Immediately after oxytocin administration;

\section{T12: At end of surgery}

The duration of surgery, amount of phenylephrine and atropine consumed in each patient were noted.

Separate anesthesiologists performed the procedure and collected the data and both were unaware of the nature of the study. The data was labeled as group 1 for normotensives and group 2 for preeclamptics and were analyzed by an anesthesiologist unaware of the nature of the study.

\section{Study definitions}

Preeclampsia: Hypertension to the extent of $140 / 90 \mathrm{mmHg}$ or more in two occasions 6 hours apart with proteinuria (More than 300 $\mathrm{mg} / 24$ hours) after $20^{\text {th }}$ week of pregnancy in a previously normotensive and non-proteinuric patient.

Booked case: Woman received antenatal care in study centre.

Significant hypotension: Systolic arterial pressure (SBP) less than 100 or fall of SBP more than $20 \%$ of the preoperative value. Treated with Phenylephrine $50 \mu \mathrm{g}$ bolus slow intravenous injection, repeated if required.

Significant bradycardia: Heart rate below 50. Treated with atropine $0.6 \mathrm{mg}$.

\section{Statistical analysis}

For sample size calculation, percentage fall of systolic blood pressure 2 minutes after subarachnoid block was considered as primary parameter. Data was obtained from a pilot study with 15 patients in each group. The power of the study was considered to be $95 \%$ with alpha error of $5 \%$. A difference of $7 \mathrm{mmHg}$ was considered to be significant. The required number of patients was calculated to be 47 and 50 patients in each group were recruited.

Kolmogorov- Smirnoff Goodness of fit test was employed to assess normality of distribution. Data was summarized as mean and standard deviation for parametric numerical variables and median and interquartile range for nonparametric numerical variables. Counts and percentages were used for categorical variables. The independent samples $t$ test was employed for intergroup comparison of parametric numerical variables or the Mann-Whitney $U$ test for non-parametrics. Categorical variables were compared between groups by Fisher's exact test. All analyses were two-tailed and $\mathrm{p}<0.05$ was considered statistically significant.

\section{Results}

Hundred patients equally distributed between the groups were included in the study and all the patients completed the study.

The demographic features including age, weight, height and body surface area were comparable between the groups. The gestational age at the time of surgery was significantly lower in the preeclampsia group $(39.26 \pm 1.19$ months in normotensives and $37.52 \pm 1.13$ in preeclamptics; $p$ value $<0.05)$. Preoperative SBP, DBP and MAP were significantly lower in the normotensive group. Preoperative heart rate was comparable between the groups ( $82.04 \pm 13.33$ beats per minute in normotensive group and $82.16 \pm 13.88$ in preeclampsia group; $\mathrm{p}$ value 0.965). Duration of surgery also similar between the groups (Table 1).

All pressures were compared in 12 specified time period and same nomenclature is followed as below:

T1: Immediately after volume preload

T2: Immediately after SAB

T3: 4 minutes after SAB

T4: 6 minutes after $S A B$

T5: 8 minutes after SAB

T6: 10 minutes after $S A B$

T7: After skin incision;

T8: After uterine incision

T9: After newborn delivery 


\begin{tabular}{|c|c|c|c|}
\hline & $\begin{array}{c}\text { Normotensive } \\
\text { group }\end{array}$ & Preeclamsia group & P value \\
\hline Age (Years) & $24.88 \pm 2.56$ & $24.22 \pm 2.41$ & 0.19 \\
\hline Weight (KG) & $63.94 \pm 4.79$ & $63.14 \pm 5.44$ & 0.438 \\
\hline Height $(\mathrm{cm})$ & $153.28 \pm 6.88$ & $153.5 \pm 7.62$ & 0.880 \\
\hline Body surface area $\left(\mathrm{m}^{2}\right)$ & $1.58 \pm 0.09$ & $1.56 \pm 0.11$ & 0.784 \\
\hline Gestational age $($ week) & $39.26 \pm 1.19$ & $37.52 \pm 1.13$ & $<0.05$ \\
\hline Preoperative SBP $(\mathrm{mmHg})$ & $126.88 \pm 12.72$ & $168.56 \pm 17.22$ & $<0.05$ \\
\hline Preoperaive DBP $(\mathrm{mmHg})$ & $78.62 \pm 9.04$ & $111.78 \pm 13.2$ & $<0.05$ \\
\hline Preoperaive MAP(mmHg) & $93.76 \pm 9.94$ & $129.4 \pm 13.04$ & $<0.05$ \\
\hline $\begin{array}{c}\text { Preoperative HR (beats per } \\
\text { minute) }\end{array}$ & $82.04 \pm 13.33$ & $82.16 \pm 13.88$ & 0.965 \\
\hline Duration of surgery (Minutes) & $44.8 \pm 7.19$ & $43.54 \pm 8.98$ & 0.44 \\
\hline
\end{tabular}

Table 1: Comparison of demography, preoperative vitals and duration of surgery.

T10: After placental delivery

T11: Immediately after oxytocin administration;

\section{T12: At end of surgery}

Comparison of systolic blood pressure (SBP) revealed significantly higher blood pressure in the preeclampsia group at different point of time during surgery as described earlier (Figure 1).

To assess the magnitude of fall of SBP between two successive observations, percentage of fall in systolic blood pressure was considered. It was calculated by the following formula:

Percentage fall $=\{($ Previous value- Current value $) /$ Previous value $\}$ $\times 100 \%$.

Comparison revealed although blood pressure rise in preeclamsia group after initial prehydration fluid bolus was higher, but difference was not statistically significant (normotensive group $3.08 \pm 0.88 \%$ versus preeclampsia group $2.88 \pm 1.6 \%$; p value 0.44 ). It indicates similar ability to handle a fluid bolus between the groups.

There was significant fall of SBP in both the groups after administration of $S A B$, but pressure fall was significantly higher in normotensive group initially $(10.39 \pm 2.77 \%$ in normotensive group versus $5.01 \pm 1.28 \%$ in preeclampsia group; $p$ value $<0.05$ at $\mathrm{T} 1$ ) but in later period significantly higher SBP fall occurred in preeclampsia group. SBP changes at later part of surgery after skin incision were similar in both groups and no statistically significant difference was found. There was a rise in SBP after placental delivery probably due to increase in blood volume and cardiac output (Figure 2).

Comparison of diastolic blood pressure (DBP) revealed significantly higher values in the preeclampsia group in all observations (Figure 3).

Percentage fall in DBP was analyzed similarly.

Percentage fall $=\{($ Previous value- Current value $) /$ Previous value $\}$ $\times 100 \%$.

The rise of blood pressure after prehydration was not significantly (statistically) different between both groups $(3 \pm 1.36 \%$ in normotensive group versus $2.31 \pm 2.39$ in preeclampsia group; p value 0.08 ). Initially fall of DBP was significantly higher in the normotensive group, but later after 4 minute it became similar in both groups. The difference was significantly higher again after delivery of baby and removal of placenta with more falls in DBP in preeclampsia group. There was no significant difference in change of DBP after placental delivery till the end of surgery (Figure 4).

Comparison of mean arterial pressure (MAP) between the groups revealed significantly lower values in all observations in normotensive group (Figure 5).

Percentage change in mean arterial pressure (MAP) also analyzed similarly. Initially, upto observations till 4 minute after SAB fall of MAP were significantly higher in normotensive group. In successive observations, fall of MAP was significantly higher in preeclampsia group. There was no significant difference between the groups in percentage fall of MAP after placental delivery till end of surgery (Figure 6)

Phenylephrine requirement was significantly higher in the normotensive group. Atropine requirement was also higher in the normotensive group but the difference was not significant (Table 2).

\section{Discussion}

The spectrum of hypertensive disorders in pregnancy encompasses four distinct forms [17-21].

1. Gestational hypertension

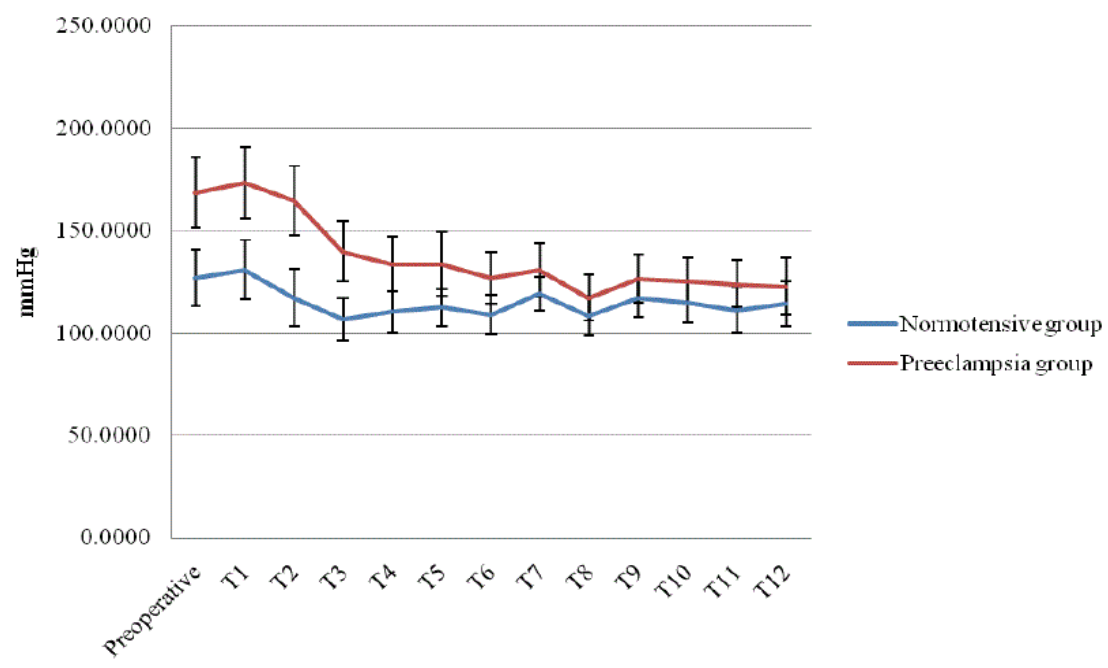

Figure 1: Systolic Blood Pressure. 


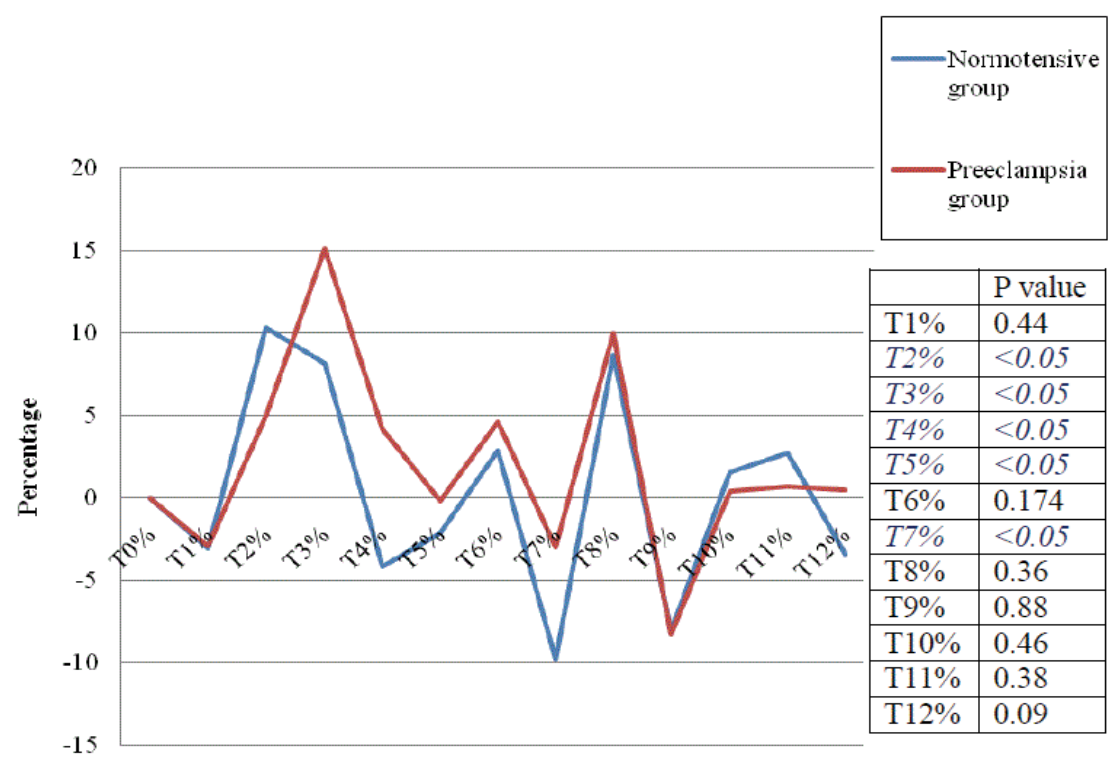

Figure 2: Percentage fall in Systolic Blood Pressure.

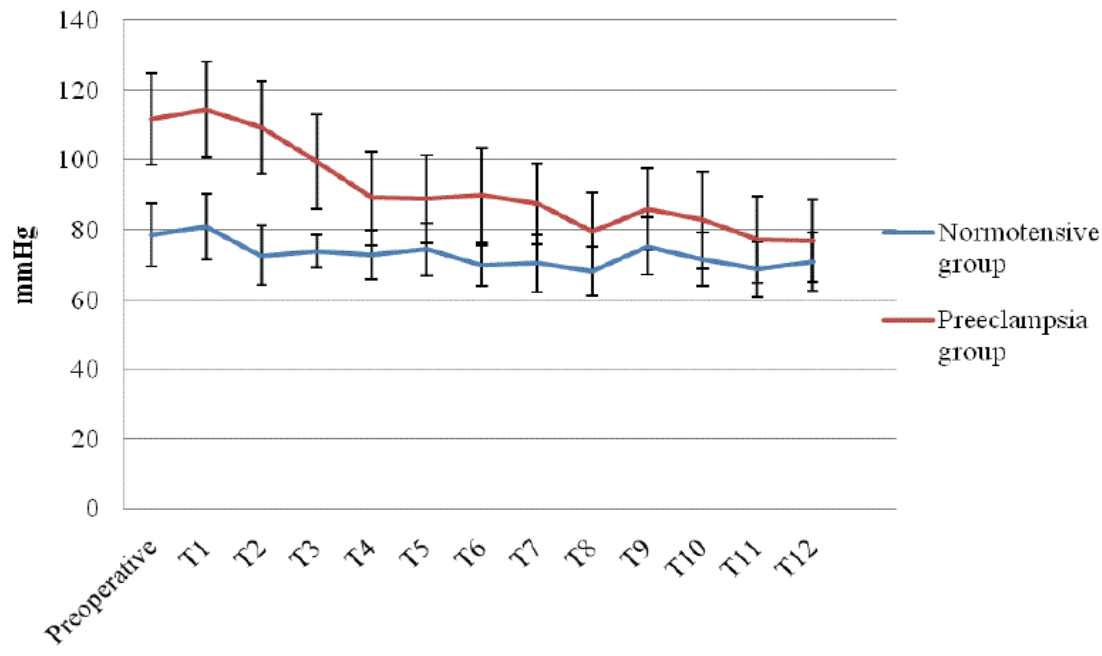

Figure 3: Diastolic Blood Pressure.

2. Pregnancy induced hyprtension (Preeclampsia-eclampsia)

3. Chronic hypertension or pre-pregnant hypertension

4. Preeclampsia superimposed on chronic hypertension.

Preeclampsia is considered unique because of is multi system involvement and unexplained etiopathenogenesis [22,23]. Incidence of preeclampsia extends from $5 \%$ of otherwise uncomplicated pregnancy to $25 \%$ of pregnant women with preexisting hypertension [22]. Exact mechanism by which preeclampsia develops are still a matter of research, basic feature of this disorder is endothelial dysfunction and intense vasospasm.

Previously, subarachnoid block (SAB) was not a preferred choice for caesarean section in parturient with severe preeclampsia [24]. The reason behind this was the possibility of severe hypotension in volume contracted individuals and those receiving antihypertensives.
However, several well conducted studies agrued against these dictums. Wallace et al. [12] conducted a randomised study to evaluate the maternal and fetal effect of $\mathrm{SAB}$ and general anesthesia in patients with severe eclampsia and found both techniques to be equally acceptable. Aya et al. [25] compared the incidence and severity of SAB associated hypotension in severely preeclamptic $(\mathrm{n}=30)$ versus healthy $(\mathrm{n}=$ 30) parturients undergoing cesarean delivery and found six times less risk of hypotension in patients with severe preeclampsia. Khatri et al. [26] conducted a similar study and found less hypotension but comparable Apgar score in patients with severe pre-eclampsia. Saha et al. [27] also found similar outcome in terms of perioperative hypotension, phenylephrine consumption and apgar score. Ahmed et al. [28] compared general anesthesia and SAB in preeclamptic toxaemia patients and opined in favour of SAB for its less severe complications. Hood and Curry [11] in a large retrospective clinical series examined the blood pressure effects of spinal and epidural anaesthesia in severely 


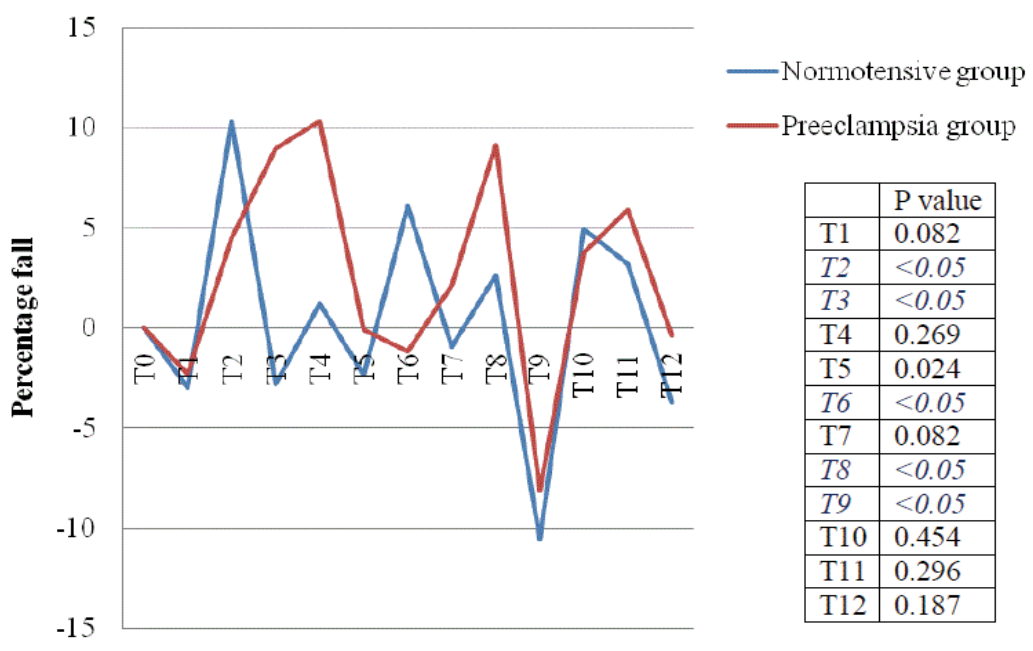

Figure 4: Percentage fall in Diastolic Blood Pressure.

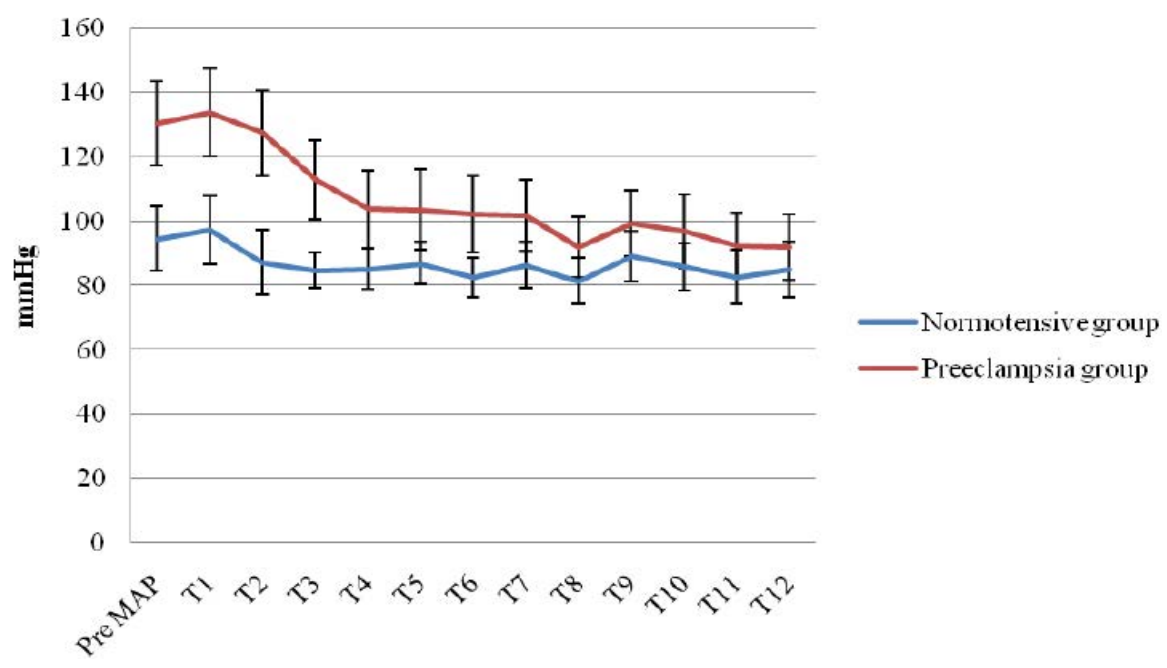

Figure 5: Mean Arterial Pressure.
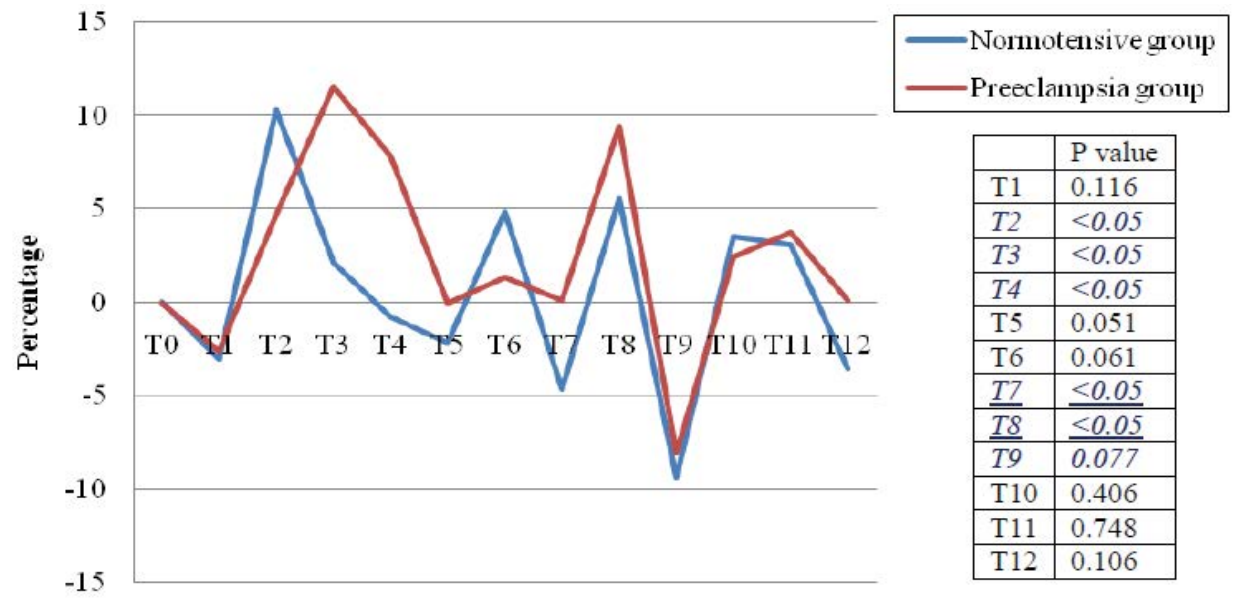

Figure 6: Pressure fall in Mean Arterial Pressure. 


\begin{tabular}{|c|c|c|c|}
\hline & Normotensive group & Preeclamptic group & P value \\
\hline Atropine & $0.41 \pm 0.26$ & $0.30 \pm 0.28$ & 0.056 \\
\hline Phenylephrine & $157.00 \pm 54.41$ & $59.00 \pm 55.96$ & $<0.05$ \\
\hline
\end{tabular}

Table 2: Phenylephrine and atropine requirement.

preeclamptic patients requiring caesarean section and found similar magnitude of decline in blood pressures as well as similar postoperative maternal and fetal outcome in both the groups. Visalyaputra et al. [13] conducted a multicentric randomised study to compare the hemodynamic effects of spinal and epidural anesthesia for cesarean delivery in severely preeclamptic patients and observed in spite of the hypotension (SBP $<$ or $+100 \mathrm{mmHg}$ ) being more frequent in the spinal group than the epidural group (51\% versus $23 \%$ ), the duration was short and it was easily treatable with ephedrine. Neonatal outcome as assessed by Apgar score and the umbilical artery blood gas analysis was similar in both the groups.

In these studies, different definitions of hypotension had been considered and incidence of hypotension have varied depending upon the chosen definition $[29,30]$. The two most frequently used definitions were a decrease of blood pressure below $80 \%$ baseline and the combined definition of a blood pressure below $100 \mathrm{mmHg}$ or a decrease below $80 \%$ baseline [29]. The authors chose the second one for better and aggressive management to maintain uteroplacental circulation.

In this study, the authors found significant differences in SBP, DBP and MAP at different point of times in both the groups. One probable explanation of this may be the use of invasive arterial blood pressure monitoring in place of noninvasive monitoring unlike other studies. Also the preoperative blood pressure values were significantly different in both the groups. This may influence the intraoperative values. More phenylephrine consumption was noted in the normotensive group. This indicated more occurrence of hypotension in the normotensive group and also contributed to the dissimilar magnitude of change in blood pressure at different point of times. The authors also emphasize on the latter fact as most of the studies compared different blood pressure values over a point of time. With a significant difference in baseline blood pressure values and significant difference in mean vasopressor consumption, the observed blood pressure values over a continuum does not truly reflect the hemodynamic alteration attributed to physiological changes imparted by SAB in both the groups. The blood pressure values reflect the combined outcome of the physiological effects, ongoing medications and anaesthesia management strategy and should be interpreted accordingly.

Volume preload before SAB is a well-established method to prevent hypotension [31-35] and $20 \mathrm{ml} / \mathrm{kg}$ of crystalloid had been shown to one of the most effective means to reduce hypotension under SAB. Although some researchers found inconsistent results [33,34], preloading and coloading is still recommended by the ASA task force to prevent hypotension associated with SAB [35]. The prehydration fluid bolus produces an atrial stretch which causes release of endogenous peptides as atrial natriuretic peptide (ANP) and endothelin-1. ANP decrease vascular tone and initiate dieresis and attenuates effect of the volume load and prevent pulmonary edema [36]. There is significantly higher release of ANP in preeclamptic women thereby helping the maternal circulation to adapt to the hemodynamic effects of fluid bolus [37]. The authors used lactated ringer's solution, $20 \mathrm{ml} / \mathrm{kg}$ in both the groups for prehydration. There was a small rise of blood pressure after volume loading in both the groups but the difference was not significant. This observation indicates that volume loading was similarly tolerated in both the groups.
Spinal anesthesia is a generally preferred anesthetic for its simple technique, rapid onset, dense block and excellent post-operative analgesia [17]. Several studies have found similar fetal outcome with $\mathrm{SAB}$ in respect to other techniques as well as in preeclamptic versus normotensive women in terms of umbilical artery blood gas values and Apgar score [26,27,38-40]. Maintenance of systolic, diastolic and mean pressure above critical values are crucial and aggressive management with vasopressors to keep the systolic pressure above $100 \mathrm{mmHg}$ or prevention of fall of blood pressure beyond $20 \%$ of baseline value are of utmost importance.

\section{Limitation and scope of further research}

The preoperative antihypertensive drugs were not protocolised properly and continued as before. This may have an impact on the blood pressure values. The blood loss was assessed from the drain output and the mops and swabs used. For appropriate assessment, quantitative measurement should have been done and the blood loss and fluid administration should have been compared. Definition of hypotension should be standardised and for this a large multicentric trial may be undertaken in future.

\section{Conclusion}

The present study is in agreement with the recent evidences that, subarachnoid block in preeclampsia patients associated with better perioperative hemodynamic stability, less hypotension, less vasopressor consumption and more gradual blood pressure changes. Prehydration strategy may be followed safely in preeclampsia patients and is recommended before subarachnoid block to ensure intraoperative stable hemodynamics.

\section{References}

1. Hawkins JL, Koonin LM, Palmer SK, Gibbs CP (1997) Anesthesia-related deaths during obstetric delivery in the United States, 1979-1990. Anesthesiology 86: 277-284.

2. Hawkins JL, Chang J, Palmer SK, Gibbs CP, Callaghan WM (2011) Anesthesiarelated maternal mortality in the United States: 1979-2002. Obstet Gynecol 117: 69-74.

3. Riley ET, Cohen SE, Macario A, Desai JB, Ratner EF (1995) Spinal versus epidural anesthesia for cesarean section: a comparison of time efficiency, costs, charges, and complications. Anesth Analg 80: 709-712.

4. Ng K, Parsons J, Cyna AM, Middleton P (2004) Spinal versus epidural anaesthesia for caesarean section. Cochrane Database Syst Rev : CD003765.

5. Flood P, Rollins MD (2010) Anesthesia for Obstetrics. Miller's Anesthesia 7th edition Philadelphia.

6. Gofton EN, Capewell V, Natale R, Gratton RJ (2001) Obstetrical intervention rates and maternal and neonatal outcomes of women with gestational hypertension. Am J Obstet Gynecol 185: 798-803.

7. Terrone DA, Isler CM, May WL, Magann EF, Norman PF, et al. (2000) Cardiopulmonary morbidity as a complication of severe preeclampsia HELLP syndrome. J Perinatol 20: 78-81.

8. Tihtonen K, Kööbi T, Yli-Hankala A, Huhtala H, Uotila J (2006) Materna haemodynamics in pre-eclampsia compared with normal pregnancy during caesarean delivery. BJOG 113: 657-663.

9. Kinzhalova SV, Makarov RA, Davydova NS (2013) Hemodynamic effects of spinal anaesthesia during caesarian section in pregnant women with hypertensive disorder. Anesteziologiia i reanimatologiia 3: 25-29.

10. Santos AC, Birnbach DJ (2003) Spinal anesthesia in the parturient with severe preeclampsia: time for reconsideration. Anesth Analg 97: 621-622.

11. Hood DD, Curry R (1999) Spinal versus epidural anesthesia for cesarean section in severely preeclamptic patients: a retrospective survey. Anesthesiology 90 1276-1282. 
Citation: Mitra M, Basu D, Ganguly T, Kar SK, Chaterjee S (2016) Comparison of the Hemodynamic Alterations in Normotensive and Preeclamptic Pregnant Woman Posted for Cesarean Section under Subarachnoid Block. J Cardiovasc Dis Diagn 4: 242. doi:10.4172/2329-9517.1000242

12. Wallace $\mathrm{DH}$, Leveno KJ, Cunningham FG, Giesecke AH, Shearer VE, et al. (1995) Randomized comparison of general and regional anesthesia for cesarean delivery in pregnancies complicated by severe preeclampsia. Obstetrics \& Gynecology 86: 193-199.

13. Visalyaputra S, Rodanant $\mathrm{O}$, Somboonviboon W, Tantivitayatan K, Thienthong $S$, et al. (2005) Spinal versus epidural anesthesia for cesarean delivery in severe preeclampsia: a prospective randomized, multicenter study. Anesthesia \& Analgesia 101: 862-868.

14. Afolayan JM, Nwachukwu CE, Esangbedo ES, Omu PO, Amadasun FE, et al. (2013) Evolving pattern of spinal anaesthesia in stable eclamptic patients undergoing caesarean section at University of Benin Teaching Hospital, Benin, Nigeria. Nigerian journal of medicine: journal of the National Association of Resident Doctors of Nigeria 23: 288-295.

15. Henke VG, Bateman BT, Leffert LR (2013) Focused review: spinal anesthesia in severe preeclampsia. Anesth Analg 117: 686-693.

16. Dyer RA, Piercy JL, Reed AR, Lombard CJ, Schoeman LK, et al. (2008) Hemodynamic changes associated with spinal anesthesia for cesarean delivery in severe preeclampsia. The Journal of the American Society of Anesthesiologists 108: 802-811.

17. Ankichetty SP, Chin KJ, Chan VW, Sahajanandan R, Tan H, et al. (2013) Regional anesthesia in patients with pregnancy induced hypertension. J Anaesthesiol Clin Pharmacol 29: 435-444.

18. Program NHBPE (2000) Report of the national high blood pressure education program working group on high blood pressure in pregnancy. American journal of obstetrics and gynecology 183: s1-s22.

19. Davey DA, MacGillivray I (1988) The classification and definition of the hypertensive disorders of pregnancy. Am J Obstet Gynecol 158: 892-898.

20. Sibai B, Dekker G, Kupferminc M (2005) Pre-eclampsia. Lancet 365: 785-799.

21. Steegers EA, von Dadelszen P, Duvekot JJ, Pijnenborg R (2010) Preeclampsia. Lancet 376: 631-644.

22. Craici IM, Wagner SJ, Weissgerber TL, Grande JP, Garovic VD (2014) Advances in the pathophysiology of pre-eclampsia and related podocyte injury. Kidney Int 86: 275-285.

23. http://www.who.int/whr/2005/en/

24. Chaudhary S, Salhotra R (2011) Subarachnoid block for caesarean section in severe preeclampsia. J Anaesthesiol Clin Pharmacol 27: 169-173.

25. Aya AG, Mangin R, Vialles N, Ferrer JM, Robert C, et al. (2003). Patients with severe preeclampsia experience less hypotension during spinal anesthesia for elective cesarean delivery than healthy parturients: a prospective cohor comparison. Anesthesia \& Analgesia 97: 867-872.

26. Khatri RK, Sethi P, Ujawal S (2014) Perioperative hemodynamic response and vasopressor requirement during spinal anesthesia for cesarean section in healthy and severe preeclamptic parturients: a prospective cohort comparison Anaesth Pain \& Intensive Care 18: 152-156.
27. Saha D, Ghosh S, Bhattacharyya S, Mallik S, Pal R, et al. (2013). Comparison of hemodynamic response and vasopressor requirement following spinal anaesthesia between normotensive and severe preeclamptic women undergoing caesarean section: A prospective study. Journal of Obstetric Anaesthesia and Critical Care 3: 23 .

28. Ahmed SM, Khan RM, Bano S, Ajmani P, Kumar A (1999) Is spinal anaesthesia safe in pre-eclamptic toxaemia patients? J Indian Med Assoc 97: 165-168.

29. Klöhr S, Roth R, Hofmann T, Rossaint R, Heesen M (2010) Definitions of hypotension after spinal anaesthesia for caesarean section: literature search and application to parturients. Acta Anaesthesiol Scand 54: 909-921.

30. Dahlgren G, Irestedt L (2010) The definition of hypotension affects its incidence. Acta Anaesthesiol Scand 54: 907-908.

31. Cyna AM, Andrew M, Emmett RS, Middleton P, Simmons SW (2010) Techniques for preventing hypotension during spinal anaesthesia for caesarean section (Review).

32. Emmett RS, Cyna AM, Andrew M, Simmons SW (2001) Techniques for preventing hypotension during spinal anaesthesia for caesarean section. Cochrane Database Syst Rev 3: CD002251.

33. Ueyama H, He YL, Tanigami H, Mashimo T, Yoshiya I (1999) Effects of crystalloid and colloid preload on blood volume in the parturient undergoing spinal anesthesia for elective Cesarean section. Anesthesiology 91: 15711576 .

34. Rout CC, Rocke DA, Levin J, Gouws E, Reddy D (1993) A reevaluation of the role of crystalloid preload in the prevention of hypotension associated with spinal anesthesia for elective cesarean section. Anesthesiology 79: 262-269.

35. (2006) ASA task force on Obstetric Anaesthesia Practice Guidelines for Obstetric Anaesthesia.

36. Pouta AM, Karinen J, Vuolteenaho OJ, Laatikainen TJ (1996) Effect of intravenous fluid preload on vasoactive peptide secretion during Caesarean section under spinal anaesthesia. Anaesthesia 51: 128-132.

37. Pouta A, Karinen J, Vuolteenaho O, Laatikainen T (1996) Pre-eclampsia: The effect of intravenous fluid preload on atrial natriuretic peptide secretion during Caesarean section under spinal anaesthesia. Acta anaesthesiologica scandinavica 40: 1203-1209.

38. Aya AG, Vialles N, Tanoubi I, Mangin R, Ferrer JM, et al. (2005) Spina anesthesia-induced hypotension: a risk comparison between patients with severe preeclampsia and healthy women undergoing preterm cesarean delivery. Anesthesia \& Analgesia 101: 869-875.

39. Chiu CL, Mansor M, Ng KP, Chan YK (2003) Retrospective review of spinal versus epidural anaesthesia for caesarean section in preeclamptic patients. Int J Obstet Anesth 12: 23-27.

40. Sharwood-Smith G, Clark V, Watson E (1999) Regional anaesthesia for caesarean section in severe preeclampsia: spinal anaesthesia is the preferred choice. Int J Obstet Anesth 8: 85-89. 